\title{
Bioprospecção e potencial biotecnológico de fungos endofíticos associados a plantas do cerrado
}

\section{Bioprospection and biotechnological potential of endophytic fungi associated to plants of Brazilian savannah}

\author{
Flavia Luana Torres ${ }^{1}$, Andréa Cristina Bogas ${ }^{1}$, Paulo Henrique Marques de Andrade $1^{1}$, Cristina \\ Paiva de Sousa ${ }^{1}$, Paulo Teixeira Lacava ${ }^{1 *}$
}

\begin{abstract}
RESUMO
Os microrganismos endofíticos são fungos ou bactérias que colonizam o interior dos tecidos vegetais sem causar dano à planta hospedeira. Os fungos endofíticos têm interessado a comunidade científica devido à produção de metabolitos secundários com aplicação nas indústrias biotecnológicas e farmacêuticas. Desta forma, o presente estudo objetivou isolar, purificar, identificar genotipicamente e avaliar a atividade antagônica, o potencial biotecnológico para solubilização fosfato e produção de enzimas de 66 fungos endofíticos de folhas e ramos isolados de S. adstringens e S. lycocarpum St. Hill. Para isso, folhas e caules saudáveis de $S$. adstringens e $S$. lycocarpum foram coletadas e submetidas à assepsia superficial. Após a incubação do material botânico procedeu-se o isolamento, identificação molecular dos fungos endofíticos. Posteriormente, os isolados endofíticos foram avaliados in vitro quanto ao potencial antagônico contra os fitopatógenos Colletotrichum sp., Fusarium oxysporum e Lasiodiplodia subglobosa, quanto a solubilização de fosfato inorgânico e a produção de enzimas (amilase, celulase, pectinase, protease, lipase e esterase). Os resultados mostraram que a comunidade endofítica fúngica associada à $S$. adstringens é composta por: Diaporthe sp., Neopestalotiopsis sp., Nigrospora sp., Paraconiothrium sp., Phomopsis sp., Pseudofusicoccum sp., Schizophyllum sp. e Xenoacremonium sp. e os gêneros da comunidade fúngica de S. lycocarpum St. Hill. é composta por: Colletotrichum sp., Curvalaria sp., Diaporthe sp., Neurospora sp., Phlebiopsis sp., Phomopsis sp. e Schizophyllum sp.. Os fungos endofíticos se mostraram promissores contra Colletotrichum sp., Fusarium oxysporum e Lasiodiplodia subglobosa sendo observados elevados índices de inibição e a maioria das interações do tipo A, onde há um bloqueio de crescimento do fitopatógeno com contato micelial do fungo endofítico. Além disso, os fungos endofíticos apresentaram potencial de solubilizar fosfato inorgânico com índice de solubilização de fosfato médio. Quanto à produção de enzimas, os isolados fúngicos de ambas as espécies vegetais apresentaram maior atividade pectinolítica com produção de pectato liase e a poligalactorose. Com base nos resultados o estudo evidencia a importância dos fungos endofíticos na produção de compostos de interesse para biotecnologia e para a conservação das espécies vegetais do Cerrado, as quais abrigam esses micro-organismos promissores.
\end{abstract}

Palavras-chaves: Cerrado; fungos endofíticos; diversidade genética; antagonismo; solubilização de fosfato; produção de enzimas.

\section{ABSTRACT}

Endophytic microorganisms are fungi or bacteria that colonize the interior of plant tissues without causing damage to the host plant. Endophytic fungi have interested the scientific community due to the production of secondary metabolites for application in the biotechnology and pharmaceutical industries. The present study aimed to isolate, purify, genotypically identify and evaluate the antagonistic activity, the

\footnotetext{
${ }^{1}$ Universidade Federal de São Carlos

*E-mail: ptlacava@ufscar.br
} 
biotechnological potential for phosphate solubilization, and the enzyme production of 66 endophytic fungi from leaves and branches isolated from $S$. adstringens and S. lycocarpum St. Hill. For this, healthy leaves and stems of $S$. astringens and S. lycocarpum were collected and submitted to superficial asepsis. After the incubation of the botanical material, it has proceeded the isolation and molecular identification of the endophytic fungi. The endophytic isolates were evaluated in vitro for the antagonistic potential against phytopathogens Colletotrichum sp., Fusarium oxysporum, and Lasiodiplodia subglobosa solubilization of inorganic phosphate and the production of enzymes (amylase, cellulase, pectinase, protease, lipase, and esterase). The results showed that the fungal endophytic community associated with $S$. adstringens is composed of: Diaporthe sp., Neopestalotiopsis sp., Nigrospora sp., Paraconiothrium sp., Phomopsis sp., Pseudofusicoccum sp., Schizophyllum sp. and Xenoacremonium sp. and the genera of the fungal community of S. lycocarpum St. Hill. is composed of Colletotrichum sp., Curvalaria sp., Diaporthe sp., Neurospora sp., Phlebiopsis sp., Phomopsis sp., and Schizophyllum sp. Endophytic fungi have shown to be promising against Colletotrichum sp., Fusarium oxysporum, and Lasiodiplodia subglobosa, with high inhibition rates and most type-A interactions, where there is a block of phytopathogen growth with mycelial contact of the endophytic fungus. In addition, endophytic fungi could solubilize inorganic phosphate with a mean phosphate solubilization index. As for enzyme production, the fungal isolates of both plant species showed higher pectinolytic activity with pectate lyase production and polygalactorosis. Based on the results, the study evidences the importance of endophytic fungi in producing compounds of interest for biotechnology and conserving Cerrado plant species, which harbor these promising microorganisms.

Keywords: Brazilian savannah; endophytic fungi; genetic diversity; antagonism; phosphate solubilization; production of enzymes.

\section{INTRODUÇÃO}

Os biomas brasileiros correspondem a uma porção expressiva da biodiversidade mundial devido aos altos níveis de riqueza de espécies fazendo com que o Brasil possua uma vocação natural para os produtos naturais (VALE et. al, 2010). Boa parte desta riqueza de espécies nativas é encontrada no mosaico de biomas do Cerrado, que atualmente por meio dos avanços das fronteiras agrícolas está entre os 25 hotspots mundiais, que são conjuntos de ecorregiões prioritárias para conservação em nível mundial (SOUSA; SERRANO; LACAVA, 2017).

Visando evidenciar a importância da conservação das espécies do Cerrado e das suas interações biológicas com o ecossistema, podem-se destacar duas plantas, Stryphnodendron adstringens (Mart), cujo nome popular é barbatimão e Solanum lycocarpum A. St. Hill., comumente chamada de lobeira, ambas com propriedades medicinais descritas na literatura. Stryphnodendron adstringens (Mart) é uma espécie da família Fabaceae e amplamente distribuída pelo Cerrado (MELO et al., 2007). A espécie $S$. adstringens possui atividade farmacológica principalmente pelo seu alto teor de taninos (LIMA et al., 2016). Além disso, possui aplicação medicinal por suas propriedades anti-inflamatórias (HENRIQUES et al., 2016), cicatrizantes (PASSARETTI et al., 2016) e antimicrobianas (LUIZ et al., 2015). Já a lobeira, Solanum lycocarpum St. Hill., que possui esse nome por ser alimento principal do lobo-guará 
atrai interesse por usada como sedativo no tratamento de epilepsia, por reduzir níveis de colesterol e no tratamento de diabetes (COSTA et al, 2015). Outras propriedades medicinais já foram descritas, como a utilização do fruto de lobeira no tratamento de asmas, gripes e resfriados (ARAUJO; COELHO; AGRA, 2010).

O barbatimão, a lobeira, assim como todas as plantas, potencialmente vivem em associação com microrganismos, os quais podem colonizar os espaços intercelulares do tecido vegetal (colonização endofítica), as superfícies dos vegetais (colonização epifítica) ou ocasionar danos aos tecidos vegetais (colonização patogênica) (LACAVA e AZEVEDO, 2013; BOGAS et al., 2020). A associação de plantas com os microrganismos é uma área de exploração científica, principalmente no Brasil, um país de clima tropical e que possui uma considerável biodiversidade de flora e de microbiota (FAVORETTO, 2010). Sendo assim, pode se destacar os endofíticos, que são bactérias e fungos, que habitam o interior das plantas, de modo geral, os caules, as raízes e as folhas, sem causar nenhuma alteração morfológica ou dano à planta hospedeira (LACAVA e AZEVEDO, 2013; BOGAS et al., 2020).

No geral, os endófitos adentram nas plantas por aberturas naturais e feridas, sendo a maior porta de entrada as raízes (MENDES e AZEVEDO, 2007). A descoberta destes microrganismos foi em 1866, pelo fitopatologista Anton DeBary, que os descreveu sendo aqueles que colonizam assintomaticamente o interior de tecidos vegetais (PEIXOTO-NETO; AZEVEDO; ARAÚJO, 2002). Nas últimas décadas, os micro-organismos endofíticos têm sido estudados principalmente como agentes de controle biológico de doenças de plantas, promotores de crescimento vegetal, produtores de enzimas e ácidos orgânicos de interesse industrial e vetores para expressão de genes heterólogos nas plantas (AZEVEDO, 2014; MAROLDI et al., 2018).

Por meio da conservação da riqueza das espécies do Cerrado, sobretudo dos vegetais, consequentemente resulta na preservação da microbiota associada aos mesmos. Além disso, estudos entre endófitos e planta é uma área com potencial significativo a se explorar (RODRIGUEZ; GONZALEZ; GIORDANO, 2016). Dentro deste contexto, o presente estudo visou estudar a diversidade filogenética de fungos endofíticos cultiváveis de folhas e ramos das espécies S. adstringens e S. lycocarpum St. Hill., e o potencial biotecnológico destes endófitos quanto a solubilização de fosfato inorgânico, produção de enzimas e biocontrole de fitopatógenos.

\section{MATERIAIS E MÉTODOS}

\section{Coleta do material vegetal}

Amostras sadias de folha e ramos de $S$. adstringes e $S$. lycocarpum foram coletadas, sob as mesmas condições climáticas e no mesmo dia, na reserva ambiental do Cerrado (21 58', 
4752’W) da Universidade Federal de São Carlos, São Carlos-SP, Brasil. Foi realizada uma única coleta de cada espécie vegetal no mês de abril de 2016, na parte manhã, em uma temperatura no local de $\pm 21^{\circ} \mathrm{C} \pm 2{ }^{\circ} \mathrm{C}$. Em seguida, as amostras foram transportadas para o Laboratório de Microbiologia e Biomoléculas (LaMiB), Departamento de Morfologia e Patologia localizado no Campus da Universidade de São Carlos, São Carlos- SP, Brasil.

Isolamento dos fungos endofíticos a partir de plantas da espécie S.adstringens e $S$. lycocarpum St. Hill.

As amostras vegetais foram lavadas em água corrente para retirada de resíduos de solo e poeira. Em seguida, os ramos e folhas foram submetidos à desinfecção superficial por imersão (ARAÚJO et al., 2014) em etanol 70\% (v/v) por um minuto, hipoclorito de sódio ( $\mathrm{NaOCl}$ ) contendo de 2 a 2,5\% de cloro ativo por dois minutos, novamente em etanol $70 \%$ (v/v) por trinta segundos sendo lavadas em água destilada esterilizada duas vezes após o processo. Após a etapa de desinfecção superficial das amostras as etapas de isolamento, purificação e estocagem foram realizadas de acordo com Araújo et al. (2014).

Extração de DNA e identificação dos fungos endofíticos pela amplificação da região ITS do rDNA

A extração de DNA dos fungos endofíticos para identificação foi realizada de acordo com método descrito por RAEDER e BRODA (1985). A amplificação da região de DNA ribossomal, o ITS-5,8S-ITS2 foi realizada pela técnica de PCR (Polymerase Chain Reaction) (SEBASTIANES et al., 2013) e utilizando os seguintes oligonucleotídeos iniciadores ITS1 (5'TCCGTAGGTGAACCTGCGG-3') e ITS 4 (5'- TCCTCCGCTTATTGATATGC-3') (WHITE et al., 1990).

\section{Identificação molecular dos fungos endofíticos isolados de barbatimão e lobeira}

As sequencias obtidas pelo sequenciamento foram utilizadas para identificação molecular dos isolados. As análises foram realizadas pelo software BioEdit Sequence Alignment Edit, onde as sequencias foram comparadas com base nos resultados observados no BLASTn e obtidas na base de dados do National Center for Biotechnology Information (NCBIhttps://www.ncbi.nlm.nih.gov/).

\section{Atividade antagônica de fungos endofíticos contra fungos fitopatogênicos in vitro}

Os fungos fitopatogênicos utilizados nos ensaios in vitro de antagonismo foram Colletotrichum sp., Fusarium oxysporum e Lasiodiplodia subglosa. Os fungos fitopatógenos utilizados fazem parte da coleção de culturas microbianas do Laboratório de Microbiologia e Biomoléculas, Universidade Federal de São Carlos, São Carlos, SP, Brasil. Os testes de 
antagonismo foram realizados de acordo com o Método da Cultura Pareada (ASSUMPÇÃO et al., 2010). Para avaliar o potencial de antagonismo dos isolados foram feitas as análises das interações endofítico-fitopatógeno baseadas na escala de Badalyan et al. (2002). O índice de antagonismo (IA) foi calculado segundo Quiroga et al., 2001.

\section{Solubilização de fosfato inorgânico}

Para analisar a capacidade dos fungos endofíticos em solubilizar fosfato inorgânico, discos de micélios foram inoculados, em três pontos diferentes da placa de Petri, em triplicada, em meio de cultura sólido contendo:10g.L-1 de glicose; 5g.L-1 de NH4Cl; 1 g.L-1 de NaCl; 1g.L1 de MgSO4 7H2O; 0,8 g.L-1 de CaHPO4; 15 g.L-1 de ágar (Kasvi); pH 7,2 a $28^{\circ} \mathrm{C}$ por 72 horas. A presença de halo incolor ao redor das colônias indicou a capacidade dos isolados em solubilizar fosfato inorgânico. (BERRAQUEIRO et al., 1976; SILVA FILHO e VIDOR, 2001).

\section{Avaliação da atividade enzimática}

A atividade enzimática dos isolados fungicos foram avaliados qualitativamente. Os ensaios avaliaram os fungos endofíticos quanto a sua capacidade de produzir enzimas, como: amilase, celulase, protease, pectinase (pH 5 e pH8), lipase e esterase (ARAÚJO et al., 2014). As placas de Petri com os ensaios enzimáticos foram incubadas a $28^{\circ} \mathrm{C}$ e observadas de acordo com o crescimento de cada fungo em cada meio específico. Os ensaios foram realizados em triplicata e como controle negativo, placas apenas com meio de cultura sem o fungo inoculado.

\section{RESULTADOS}

\section{Isolamento de fungos endofiticos de Stryphnodendron adstringens - Barbatimão e Solanum} lycocarpum St. Hill .- Lobeira

A partir do isolamento dos fungos endofíticos por fragmentação do tecido vegetal de folhas e de ramos foram obtidos, respectivamente quinze fungos endofíticos de folhas e seis de ramos, totalizando vinte e um isolados endofíticos. O maior número de fungos endofíticos isolados foram nos fragmentos de folhas. Dos fragmentos de folhas de Solunum. lycocarpum St. Hill. foram isolados trinta e dois fungos endofíticos e de ramos foram obtidos treze isolados resultando em quarenta e cinco no total. Similar ao resultado encontrado no barbatimão, o maior número de fungos endofíticos isolados foram nas folhas de lobeira. Na Figura 1 é possível observar a diversidade fenotípica dos isolados fúngicos endofíticos obtidos. 
Figura 1 - Amostragem da diversidade de fungos endofíticos de Stryphnodendron adstringens (A) e Solanum lycocarpum St. Hill. (B) encontradas no Cerrado de São Carlos, estado de São Paulo.
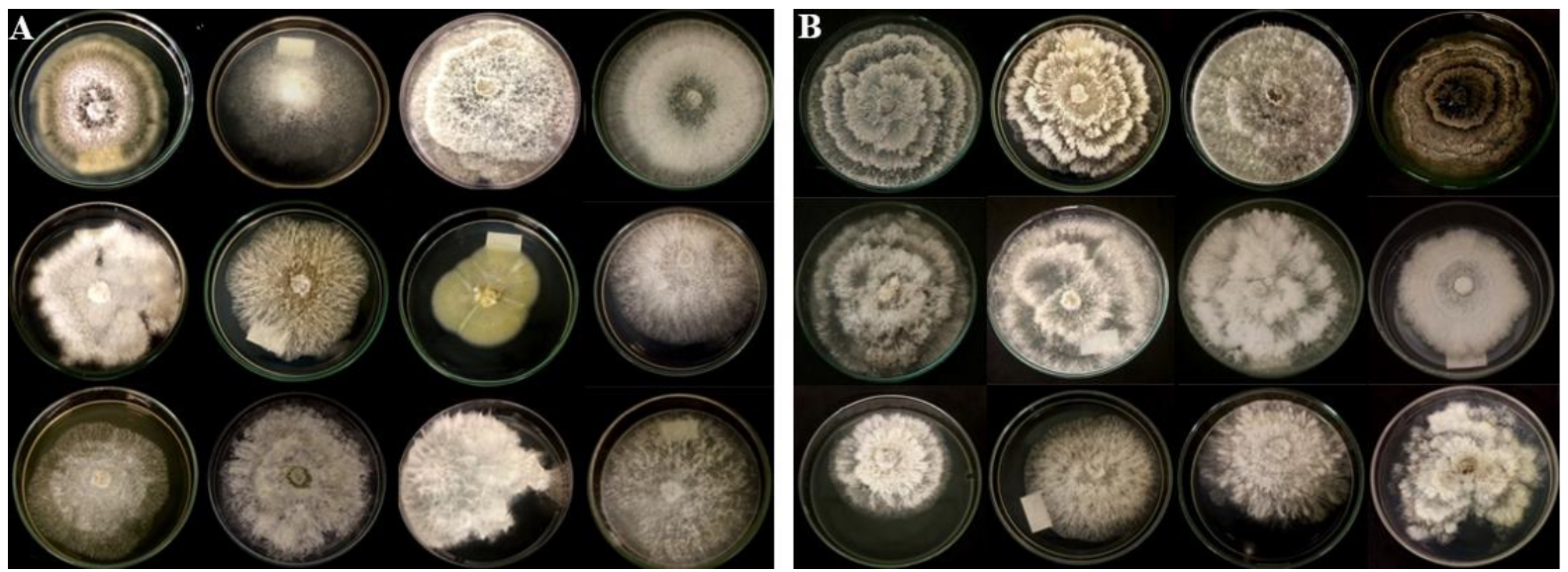

Fonte: F. L. Torres (2018).

\section{Identificação molecular dos fungos endofíticos}

Os fungos endofíticos associados à $S$. adstringens foram submetidos ao sequenciamento da região ITS1-5,8S-ITS2 do rDNA e as sequencias obtidas foram comparadas com aquelas depositadas com a utilização da ferramenta BLASTn no banco de dados do NCBI. Por meio do sequenciamento foi observado que a comunidade endofítica fúngica associada à $S$. adstringens é composta pelos seguintes gêneros Diaporthe, Neopestalotiopsis Nigrospora, Paraconiothrium, Phomopsis Pseudofusicoccum,

Schizophyllum e Xenoacremonium e a comunidade associada a S. lycocarpum St. Hil. é Colletotrichum sp., Curvalaria sp., Diaporthe sp., Neurospora sp., Phlebiopsis sp., Phomopsis sp. e Schizophyllum sp. Os mais dominantes foram Phomopsis sp. e Diaporthe sp.

\section{Atividade antagônica dos fungos endofíticos contra fitopatógenos}

Dos 21 fungos endofíticos avaliados contra os fungos fitopatogênicos, quatro apresentaram alguma atividade antagônica contra os fungos Colletotrichum sp., cinco contra Fusarium oxysporum e três contra Lasiodiplodia subglobosa. Das interações apresentadas entre endófitos e fitopatógenos, três apresentaram interação do tipo A, com deadlock com contato micelial e um apresentou interação do tipo CA1, com crescimento parcial do endofítico sobre o fitopatógeno depois de deadlock inicial com contato micelial contra Colletotrichum sp., cinco apresentaram interação do tipo A contra $F$. oxysporum e três apresentaram interação do tipo A contra L. subglobosa. Observou-se que para ambos fitopatógenos a predominância das interações foi do tipo A, seguida da interação CA1. No Colletotrichum sp. o índice de antagonismo (IA\%) (QUIROGA et al. 2001) variou de $35,71 \%$ a $85,36 \%$. Contra o $F$. oxysporum, o índice de antagonismo variou entre $8,33 \%$ a $62,02 \%$ e contra $L$. subglosa variou de $28,57 \%$ a $45 \%$. Na 
Figura 2 é possível verificar um exemplo de interação antagônica entre um isolado endofítico e um dos fungos fitopatogênicos testados.

Figura 2 - Exemplo de interação antagônica entre um isolado endofítico (BF01/Barbatimão/Folha) e um fungo fitopatogênico. (a) Interação tipo A, deadlock com contato micelial entre o endófito e o fitopatógeno (LFO1/direita e Colletotrichum sp./esquerda). (b) Controle experimental, onde há apenas o cultivo do Colletotrichum sp..
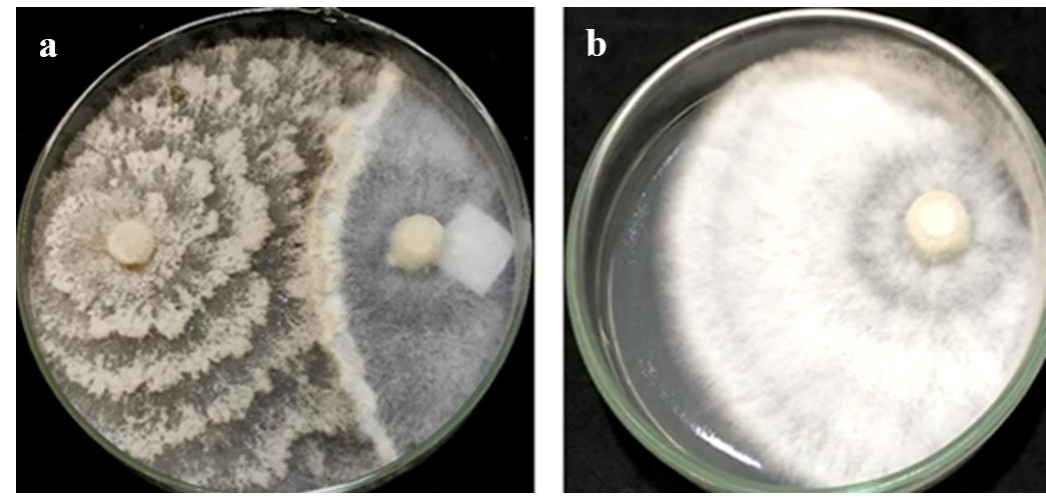

Fonte: F. L. Torres (2018).

Dos 45 fungos endofíticos isolados de folhas e ramos de Solanum lycocarpum St. Hill., 5 apresentaram atividade antagônica contra Colletotrichum sp., 8 contra $F$. oxysporum e 2 contra $L$. subglobosa. Das interações contra Colletotrichum sp. a do tipo A, com deadlock com contato micelial foi a mais recorrente, mas 2 fungos endofíticos apresentaram interação do tipo CA1, com crescimento parcial do endofítico sobre o fitopatógeno depois de deadlock inicial com contato micelial. Dos 8 endófitos com atividade antagônica contra $F$. oxysporum, 6 apresentaram interação do tipo A e 2 do tipo CA1. Já contra o fitopatogeno L. subglobosa, 1 apresentou interação do tipo A e o outro do tipo CA1. O índice de antagonismo contra Colletotrichum sp. variou de $37,66 \%$ a $52 \%$, em $F$. oxysporum variou de $9,58 \%$ a $65,71 \%$ e com L. subglobosa variou de $58,22 \%$ a $74,13 \%$.

\section{Solubilização de fosfato pelos fungos endofíticos isolados}

Dos vinte e um fungos endofíticos isolados de folhas e ramos de Stryphnodendron adstringens avaliados quanto a capacidade de solubilizar fosfato em meio sólido contendo CaHPO4, oito $(38,09 \%)$ apresentaram halo em torno das colônias e indicaram potencial de solubilização de fosfato pelos mesmos. De acordo com Silva Filho e Vidor (2001), os isolados que apresentaram resultado positivo para solubilização de fosfato podem ser classificados em três classes: Isolados com baixo potencial de solubilização (ISF<2), com médio potencial de solubilização $(2>\mathrm{ISF}<3)$ e com alto potencial de solubilização $(\mathrm{ISF}<3)$. Os isolados de lobeira apresentaram índice de solubilização de fosfato (ISF) menor que 1, desta forma foram 
classificados com baixo potencial de solubilização de fosfato. Dos quarenta e cinco fungos endofíticos isolados de folhas e ramos de Solanum lycocarpum St. Hill. avaliados quanto a capacidade de solubilizar fosfato em meio sólido contendo $\mathrm{CaHPO}_{4}$, vinte e três $(51,11 \%)$ apresentaram halo em torno das colônias e indicaram potencial de solubilização de fosfato pelos mesmos. O índice de solubilização de fosfato dos isolados de lobeira variou entre baixo (ISF>2) a médio $(2>\mathrm{ISF}<3)($ SILVA FILHO e VIDOR, 2001). O isolado LRA3 apresentou o melhor potencial de solubilização de fosfato dentre demais isolados, com ISF de 2,61. (Figura 3).

Figura 3 - Exemplo da avaliação de um isolado endofítico (LRA3/Lobeira/Raiz) quanto a capacidade solubilizar fosfato em meio de cultura sólido contento fosfato de cálcio insolúvel. Os halos em torno das colônias fúngicas (A, B e C) são indicadores de solubilização.

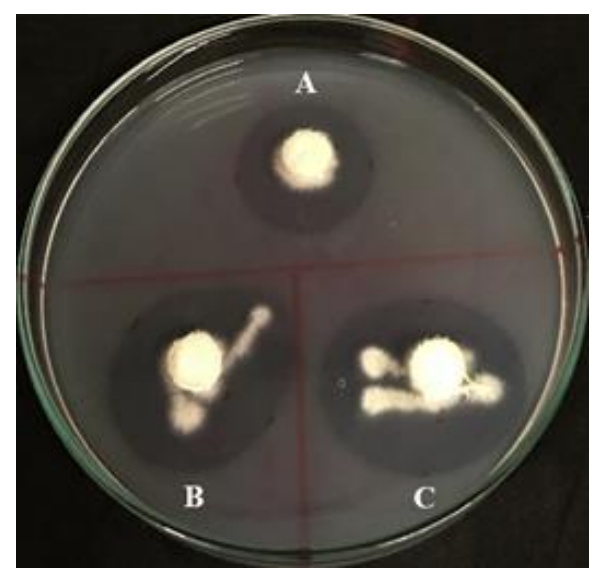

Fonte: F. L. Torres (2018).

Produção enzimática por fungos endofíticos de Stryphnodendron adstringens e Solanum lycocarpum St. Hill.

Os fungos endofíticos isolados de folhas e ramos de barbatimão e lobeira, apresentaram atividade amilolítica, celulolítica, pectinolítica, pectato liase, poligalacturonase, proteolítica, esterásica e lipolítica. O isolado com maior potencial enzimático é o BFO4 (folha), pois apresentou atividade para produção de todas as enzimas testadas. Dos isolados mais promissores, o BRA5 (ramo) e o BRA6 (ramo) se destacaram, pois apresentaram maior potencial de atividade para produção de quatro tipos de enzimas diferentes, ambos apresentaram atividade para amilase, celulase, poligalactoronase. O isolado LFO3 apresentou atividade para celulase, pectato liase, poligalacturonase, protease, lipase e esterase, sendo assim o isolado com maior potencial de produção de enzimas isolado de lobeira. Os isolados que apresentaram melhores resultados foram LRA7 e LRA8, que apresentaram atividade para cinco enzimas, pectato liase, poligalactoronase, protease e lipase, sendo que o LRA7 também apresentou atividade amilolítica e o LRA8 para celulase. Exemplos de resultados positivos para a atividade enzimática pelos fungos endofíticos podem ser verificadas na Figura 4. 
Figura 4 - Exemplos de resultados positivos de avaliação enzimática em ensaios in vitro para as seguintes enzimas A) Amilase, B) Pecto liase, C) Celulase e D) Protease.

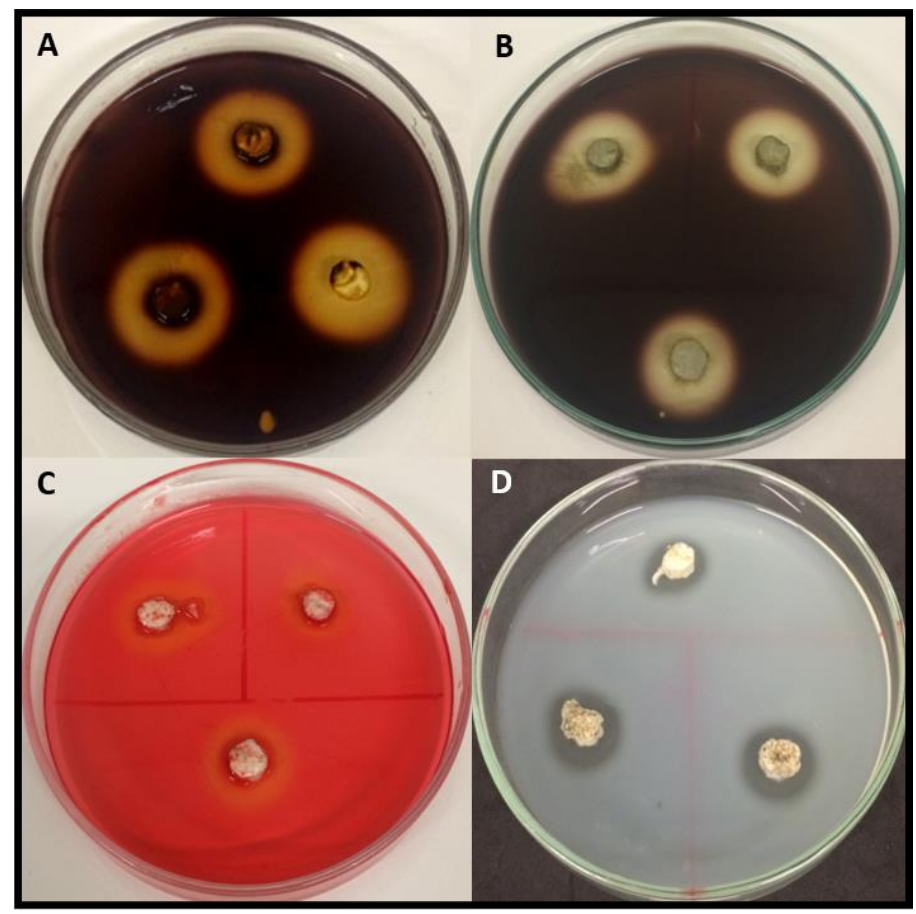

Fonte: F. L. Torres (2018).

\section{DISCUSSÃO}

Com o isolamento de fungos endofíticos de folhas e ramos de $S$. adstringens foi possível a identificação dos seguintes gêneros Diaporthe, Neopestalotiopsis Nigrospora, Paraconiothrium, Phomopsis Pseudofusicoccum, Schizophyllum e Xenoacremonium, já descritos como endófitos (SHETTY et al., 2016; UZOR; OSADEBE; NWODO, 2017). Em um estudo realizado por Carvalho et al. (2012) de diversidade de fungos endofíticos associados a $S$. adstringens, demostrou que a comunidade endofítica fúngica possui alta riqueza constituída por gêneros que foram isolados no presente estudo, como Nigrospora, Paraconiothyrium. Além disso, Diaporthe, Phomopsis e Pseudofusicoccum foram os mais frequentes, corroborando com os dados do estudo em questão.

Na espécie vegetal S. lycocarpum St. Hill., os gêneros predominantes foram Phomopsis sp. e Diaporthe sp.. Vieira et al. (2014) também descreve o fungo endofítico Diaporthe phaseolorum como a gênero mais frequente que ocorre numa outra planta medicinal do Cerrado, Baccharis trimera, evidenciando assim que este gênero fúngico é comumente presente em espécies vegetais deste bioma. Nesse mesmo sentido, em um outro estudo de fungos endofíticos associados a Dalbergia odorifera $\mathrm{T}$. Chen, demostrou que dentre os gêneros frequentemente isolados endofiticamente está incluso o Phomopsis (SUN et al., 2015). Estes dois gêneros, 
Diaporthe e Phomopsis são um dos endófitos mais encontrados ramos e folhas de angiosperma de ecossistemas tropicais (UDAYANGA et al., 2011). Outros gêneros também foram descritos na comunidade endofitica de S. lycocarpum St. Hill., como o Colletotrichum sp., Curvalaria sp, Neurospora sp, Phlebiopsis sp e Schizophyllum sp.. Em relação ao trabalho de Vieira et al. (2008), que estudou a diversidade de fungos endofíticos isolados de ramos e folhas de uma planta medicinal, Solanum cernuun Vell., que corresponde ao mesmo gênero da lobeira, foi observado que o Colletotrichum sp. está entre os gêneros frequentemente isolados. Além disso, gêneros como Curvalaria sp., Phlebiopsis sp., Schizophyllum sp. também foram descritos na comunidade fúngica endofítica desta espécie vegetal do cerrado.

Gêneros fúngicos tais como Colletotrichum sp. e Curvalaria sp. são comumente descrito como endófitos (TAWFIKE; ABBOTT; YOUNG, 2018; HUANG et al., 2018) e possuem potencial antimicrobiano contra Staphylococcus aureus, Bacillus subtilis e Micrococcus luteus (HORMAZABAL e PIONTELLI, 2009). O gênero. Neurospora sp. também foi descrito como endófito por Sebastianes et al. (2013) pertencendo a comunidade fúngica de espécies vegetais de manguezais e produtor de camptotecina, um alcaloide citotóxico com atividade antitumoral (REHMAN et al., 2008).

Nos ensaios in vitro de antagonismos contra Colletotrichum sp., Fusarium oxysporum e Lasiodiplodia subglobosa observou-se que dos vinte e um fungos endofíticos de barbatimão avaliados, quatro apresentaram atividade antagônica contra o fungo Colletotrichum sp., o isolado BFO1, BRA1, BRA2, sendo que o isolado BRA3 apresentou o maior índice de antagonismo, com 85,36\% de inibição do fitopatógeno. Contra $F$. oxysporum, cinco fungos apresentaram potencial contra o fitopatógeno, o isolado BFO1, BFO9, BRA2, BRA3, sendo que o BRA1 apresentou maior índice de antagonismo 62,02\%. Contra L. subglobosa, três isolados apresentaram atividade antagônica BRA2, BRA3 e BRA4, que apresentou maior índice de antagonismo com 45\% de inibição. Os isolados BRA2, BRA3 e BRA4 correspondem ao gênero Pseudofusicoccum sp. e há relato da capacidade antagônica, uma vez que este gênero apresentou atividade antifúngica contra C. cladosporioides e C. sphaerospermum (RAHMÉ, 2018). O outro isolado que obteve atividade antagônica contra dois fitopatógenos foi o BFO1, que corresponde ao gênero Nigrospora sp., com atividade biológica descrita devido a produção metabólitos secundários com ação antifúngica, como a griseofulvina. Esse gênero apresentou potencial antagônico contra 8 fungos fitopatogênicos, dentre eles $F$. oxysporum e Colletotrichum orbiculare (ZHAO et al., 2012).

No ensaio in vitro com os fungos endofíticos de S. lycocarpum St. Hil, cinco apresentaram atividade antagônica contra Colletotrichum sp., oito contra F. oxysporum e dois contra L. subglobosa. O isolado fungíco com maior índice de antagonismo contra Colletotrichum sp. foi o LFO1 com 52\%, LRA 13 contra F. oxysporum com 65,71\% e LRA4 que reduziu a área do fitopatógeno L. subglobosa em 74,13\%. Os isolados com maior índice de 
antagonismo ainda serão identificados molecularmente. Os gêneros Phomopsis e Diaporthe apresentaram potencial antagônico contra $F$. oxysporum. Ambos são gêneros descritos na literatura com potencial antifúngico, o Diaporthe sp. por apresentar atividade antagônica contra Phytophthora infestans, fitopatógeno que acomete culturas de batata e tomate, ambas espécies do gênero Solanum (PRADA et al., 2009) e o Phomopsis sp. que apresentou atividade antagônica inibindo o crescimento de Rhizoctonia solani por competição por nutrientes e espaço (LAHLALI e HIJRI, 2010).

Tantos os fungos endofíticos de barbatimão quanto os de lobeira apresentaram na sua maioria a interação do tipo A, a qual inibe o crescimento do fitopatógeno com contato micelial. Os fungos endofíticos podem atuar contra os fitopatógenos reduzindo o crescimento e o desenvolvimento dos mesmos competindo por espaço, por nutrientes e se estabelecendo de modo que reduza o crescimento do fitopatógeno. Resultado semelhante foi obtido por BernardiWenzel et al. (2012) que isolou fungos endofíticos de soja e os testou contra A. solani, F. solani, Phomopsis sp. e R. solani e avaliando as interações dos endófitos com os fitopatógenos e obteve predominância da interação tipo A com 64\%. Os resultados obtidos no presente trabalho mostram que os fungos endofíticos de barbatimão e lobeira possuem potencial para aplicação no controle biológico de fitopatógenos sendo uma opção para reduzir ou até mesmo eliminar o uso de agroquímicos.

Os microrganismos podem ser ferramentas importantes no ciclo natural do fósforo disponibilizando o elemento que está insolúvel nos solos em solúvel e disponível as plantas (LACAVA; MACHADO; DE ANDRADE, 2021). Entre os gêneros de fungos que são conhecidos por esta capacidade destacam-se o Aspergillus e Penicillium (SILVA-FILHO et al., 2001). No presente estudo, $38,09 \%$ dos isolados fúngicos de barbatimão foram capazes de solubilizar fosfato, já dos fungos endofíticos de lobeira $51,11 \%$ solubilizaram fosfato. Dos isolados de lobeira quatro apresentaram índices médios de solubilização e ambos os fungos foram isolados de ramos. A maioria dos fungos com potencial de solubilizar fosfato são os de solo devido suas características intrínsecas de solubilidade de fosfato como adaptações de colonizar este tipo de ambiente (COUTINHO; CAVALCANTI; YANO-MELO, 2011). Embora os microrganismos de solo sejam potencialmente mais utilizados, os fungos endofíticos são capazes de solubilizar fosfato e são importantes para contribuir no crescimento vegetal e reduzir a necessidade de fertilizantes (LACAVA; MACHADO; DE ANDRADE, 2021).

A produção de enzimas é um setor importante para biotecnologia industrial uma vez que esses catalisadores biológicos são capazes de acelerar processos químicos e são ecologicamente viáveis (ANGELO, 2010). Embora as enzimas mais estudadas sejam as de origem animal e vegetal, as enzimas microbianas apresentam potencial para aplicação industrial, uma vez que podem ser produzidas em larga escala e são facilmente expressas nos organismos (ORLANDELLI et al., 2012). O estudo do perfil enzimático in vitro dos fungos endofíticos de 
folhas de barbatimão mostrou que estes possuem potencial para produção de todas as enzimas testadas, contudo, os isolados fúngicos apresentaram maior potencial para produção de pectinases, sendo que nove (60\%) dos quinze isolados produziram pectato liase. Os seis isolados fúngicos de ramos de barbatimão apresentaram atividade para produção de todas as enzimas testadas exceto a esterase. Todos os endófitos apresentaram atividade pectinolítica para poligalacturonase.

Os fungos endofíticos associados à lobeira possuem potencial de produzir as enzimas testadas, sendo que dos trinte e dois, vinte e dois $(68,75 \%)$ isolados de folhas apresentaram maior atividade para produção de poligalacturonase. Dos treze isolados fúngicos de ramos, onze $(84,61 \%)$ apresentaram produção da enzima pectato liase.

Os fungos endofíticos tem alta habilidade de produzir enzimas líticas, como as pectinases, celulases e lipases. Essas enzimas são produzidas pelos endófitos para auxiliar na entrada dos mesmos no tecido vegetal, na obtenção de nutrientes e são necessárias para os fungos superarem o mecanismo de defesa do hospedeiro durante a colonização. Fungos com alta atividade lipolítica possuem alta capacidade de usar gordura como fonte de energia (SUNITHA; DEVI; SRINIVAS, 2013; CORREA et al., 2014). Além disso, os endófitos são produtores de enzimas hidroliticas como as proteases, essas são usadas no controle biológico de fitopatógenos, pois degradam paredes celulares das suas hifas (ORLANDELLI et al., 2012).

Suryanarayanan et al. (2003) reportou que fungos endofíticos isolados da floresta tropical da Índia (Western Ghats) apresentaram atividade para produção de amilase, celulase, pectato liase, protease e lipase; sendo esta última a mais produzida entre os isolados fúngicos testados (84\%). Cuzzi et al. (2011) avaliou o potencial dos fungos endofíticos do alecrim do campo, Baccharis dracunculifolia, na produção de enzimas extracelulares, os isolados apresentaram atividade na produção de lipase, amilase e protease. Fungos endofíticos associados às sementes do guaranazeiro apresentaram atividade na produção de enzimas extracelulares, desta forma, todos os isolados fúngicos testados apresentaram atividade pectinolítica, amilolítica e lipolítica (SILVA, 2015). Outro estudo que se assemelha aos resultados do presente trabalho verificou os fungos endofíticos associados à plantas medicinais, os quais apresentaram atividade na produção de enzimas extracelulares, sendo que $64 \%$ dos isolados apresentaram atividade para lipase, $62 \%$ para pectinase e amilase e $32 \%$ para celulase (SUNITHA; DEVI; SRINIVAS, 2013) mostrando que os resultados coincidem com os do presente trabalho, uma vez que os endófitos isolados de folhas de lobeira apresentaram maior atividade pectinolítica (poligalacturonase) com 68,75\% e atividade lipolítica (65,62\%). Além disso, a produção enzimática dos fungos endofíticos é variável e está relacionada com a planta hospedeira (TAN e ZOU, 2001), isso mostra que os endófitos de plantas medicinais podem apresentar maior atividade pra estes tipos de enzimas. 
Os isolados fúngicos que apresentaram maior atividade na produção das enzimas testadas foram Neopestalotiopsis sp. (isolado BFO4), Xenoacremonium sp. (isolado BRA5), Paraconiothrium sp, e Phomopsis sp.,com base nos resultados revela a produção de enzimas hidroliticas por fungos endofíticos tem potencial para exploração e aplicação em vários setores industriais (ÂNGELO, 2010; MAROLDI et al., 2018).

\section{REFERÊNCIAS}

ÂNGELO, R. S. Enzimas hidrolíticas. In: Esposito, E.; Azevedo, J. L. (Ed), Fungos, uma introdução à biologia, química e biotecnologia, 2nd edn. Universidade Caxias do Sul, Rio Grande do Sul, 2010, p. 533-569.

ARAÚJO, N. D.; COELHO, V. P. D. M.; AGRA, M. D. F. The pharmacobotanical comparative study of leaves of Solanum crinitum Lam., Solanum gomphodes Dunal and Solanum lycocarpum A. St-Hil,(Solanaceae). Revista Brasileira de Farmacognosia, v. 20, n. 5, p. 666-674, 2010.

ARAÚJO, W. L.; QUECINE, M. C.; LACAVA, P. T.; AGUILAR-VILDOSO, C. I.; MARCON, J.; LIMA, A. O. S.; KUKLINSKY-SOBRAL, J.; PIZZIRANI-KLEINER, A. A.; AZEVEDO, J. L. Micro-organismos Endofíticos: Aspectos Teóricos e Práticos de Isolamento e Caracterização. 1 $^{\mathrm{a}}$. ed. Santarém: UFOPA, 2014.

ASSUMPÇÃO, L. C.; LACAVA, P. T.; DIAS, A. C. F.; AZEVEDO, J. L.; MENTEN, J. O. M. Diversidade e potencial biotecnológico da comunidade bacteriana endofítica de sementes de soja. Pesquisa Agropecuária Brasileira, v. 44, n. 5, p. 503-510, 2010.

AZEVEDO, J. L. Endophytic fungi from Brazilian tropical hosts and their biotechnological applications. In: KHARWAR, R. N.; UPADHYAY, R.; DUBEY, N.; RAGHUWANSH, R. (Ed) Microbial diversity and biotechnology in food security, Springer, New Delhi, 2014, p. 17-22.

BERNARDI-WENZEL, J.; SIQUEIRA, A. L.; BURIN, F. A. G.; HEIN, D. P. R.; SILVEIRA, J.; ROMANI, S. Isolamento e atividade antagonística de fungos endofíticos isolados de soja (Glycine max L.(Merril)). SaBios: Revista de Saúde e Biologia, v. 7, n. 3, p. 86-96, 2012.

BERRAQUEIRO, F.R.; BAYA, A. M.; CORMENZANA, A. R .Establecimiento de índices para el estudio de la solubilizacion de fosfatos por bacterias del suelo. ARS Pharm v. 17, p. 399-406, 1976.

BOGAS, A. C.; TORRES, F. L.; SOUSA, C. P.; LACAVA, P. T. Bioactivity of endophytes from the Brazilian tropical savannah. Acta Scientific Microbiology, v. 3, p. 15-22, 2020.

CARVALHO, C. R.; GONÇALVES, V. N.; PEREIRA, C. B.; JOHANN, S. GALLIZA, I. V.; ALVES, RABELLO A; SOBRAL, M. E. G.; ZANI, C. L.; ROSA C. A; ROSA, L. $\mathrm{H}$. The diversity, antimicrobial and anticancer activity of endophytic fungi associated 
with the medicinal plant Stryphnodendron adstringens (Mart.) Coville (Fabaceae) from the Brazilian savannah. Symbiosis, v. 57, n. 2, p. 95-107, 2012.

COMBÈS, A.; NDOYE, I.; BANCE, C.; BRUZAUD, J.; DJEDIAT, C.; DUPONT, J.; NAY, B.; PRADO, S. Chemical communication between the endophytic fungus Paraconiothyrium variabile and the phytopathogen Fusarium oxysporum. PLoS One, v. 7, n. 10, p. e47313, 2012.

CORREAA, R. C. G.; RHODEN, S. A.; MOTA, T. R.; AZEVEDO, J. L.; PAMPHILE, J. A.; SOUZA, C. G. M.; BRACHT, A.; PERALTA, R. M. Endophytic fungi: expanding the arsenal of industrial enzyme producers. Journal of industrial microbiology \& biotechnology, v. 41, n. 10, p. 1467-1478, 2014.

COSTA, G. A. F.; MORAIS, M. G.; SALDANHA, A. A.; SILVA, A.; CAPUTO, I.; ALEIXO, Á. A.; FERREIRA, J. M. S.; SOARES, A. C.; DUARTE-ALMEIDA, J. M.; LIMA, L. A. R. D. S. Antioxidant, antibacterial, cytotoxic, and anti-inflammatory potential of the leaves of Solanum lycocarpum A. St. Hil.(Solanaceae). Evidence-Based Complementary and Alternative Medicine, v. 2015, 2015.

COUTINHO, F. P.; CAVALCANTI, M. A. D. Q.; YANO-MELO, A. M. Phosphatesolubilizing fungi isolated from a semiarid area cultivated with melon (Cucumis melo $\mathrm{L}$. cv. gold mine). Acta Botanica Brasilica, v. 25, n. 4, p. 929-931, 2011.

CUZZI, C.; LINK, S.; VILANI, A.; ONOFRE, S. B. Enzimas extracelulares produzidas por fungos endofíticos isolados de Baccharis Dracunculifolia DC (ASTERAECEAE). Global Science and Technology, v. 4, n. 2, 2011.

FAVORETTO, N. B. Produção de substancias bioativas por micro-organismos endofíticos isolados do Cerrado de São Carlos-SP. Dissertação de mestrado. Universidade Federal de São Carlos - UFSCar, 2010.

GANGADEVI V.; MUTHUMARY J. Isolation of Colletotrichum gloeosporioides, a novel endophytic taxol-producing fungus from the leaves of a medicinal plant, Justicia gendarussa. Mycologia Balcanica, v. 5, p. 1-4, 2008.

HENRIQUES, B. O.; CORRÊA, O.; AZEVEDO, E. P. C.; PÁDUA, R. M.; OLIVEIRA, V. L. S. D.; OLIVEIRA, T. H. C.;TEIXEIRA, M. M. In vitro TNFinhibitory activity of Brazilian plants and anti-inflammatory effect of Stryphnodendron adstringens in an acute arthritis model. Evidence-Based Complementary and Alternative Medicine, 2016.

HORMAZABAL E; PIONTELLI E. Endophytic fungi from Chilean native gymnosperms: antimicrobial activity against human and phytopathogenic fungi. World J Microbiol Biotechnol, v.25, p. 813-19, 2009.

HUANG, J., H.; XIANG, M., M.; JIANG, Z., D. Endophytic fungi of bitter melon (Momordica charantia) in Guangdong Province, China. The Great Lakes

Entomologist, v.45, n. 1 \& 2, p. 2, 2018. 
LACAVA, P. T.; AZEVEDO, J. L. Endophytic bacteria: a biotechnological potential in agrobiology system. In: Bacteria in Agrobiology: Crop Productivity. Springer, Berlin, Heidelberg, p. 1-44, 2013.

LACAVA, P. T.; MACHADO, P. C.; DE ANDRADE, P. H. M. Phosphate Solubilization by Endophytes from the Tropical Plants. In: Maheshwari D.K.; Dheeman S.. (Org.). Sustainable Development and Biodiversity. 26ed.Springer Nature Switzerland AG: Springer International Publishing, 2021, v. 3, p. 207-226.

LAHLALI, R.; HIJRI, M. Screening, identification and evaluation of potential biocontrol fungal endophytes against Rhizoctonia solani AG3 on potato plants. FEMS Microbiology Letters, v. 311, n. 2, p. 152-159, 2010.

LIMA, T. C. D. D.; CARDOSO, M. V.; MODESTO, T.; OLIVEIRA, A. L. D. B.; SILVA, M. N. D.; MONTEIRO, M. C. Breve revisão etnobotânica, fitoquímica e farmacologia de Stryphnodendron adstringens utilizada na Amazônia, Revista Fitos, v.10, n.3, p. 220-372, 2016.

LUIZ, R. L. F.; VILA, T. V. M.; MELLO, J. C. P.; NAKAMURA, C. V.; ROZENTAL, S.; ISHIDA, K. Proanthocyanidins polymeric tannin from Stryphnodendron adstringens are active against Candida albicans biofilms. BMC complementary and alternative medicine, v15, n.1, p.68, 2015.

MAROLDI, M. M. C.; VASCONCELLOS, V. M.; LACAVA, P. T.; FARINAS, C. S. Potential of Mangrove-Associated Endophytic Fungi for Production of Carbohydrolases with High Saccharification Efficiency. Applied biochemistry and biotechnology, v. 184, n. 3, p. 806-820, 2018.

MELO, J. O. D.; ENDO, T. H.; BERSANI-AMADO, L. E.; SVIDZINSKI, A. E.; BARONI, S.; MELLO, J. C. P. D.; BERSANI-AMADO, C. A. Effect of Stryphnodendron adstringens (barbatimão) bark on animal models of nociception. Revista Brasileira de Ciências Farmacêuticas, v.43, n.3, p.465-469, 2007.

MENDES, R.; AZEVEDO, J. L. Valor biotecnológico de fungos endofíticos isolados de plantas de interesse econômico. Micologia: avanços no conhecimento. Brazilian Society Microbiology Publ., Recife, p. 129-140, 2007.

ORLANDELLI, R. C.; ALBERTO, R. N.; RUBIN FILHO, C. J.; PAMPHILE, J. A. Diversity of endophytic fungal community associated with Piper hispidum (Piperaceae) leaves. Genet Mol Res, v.11, n.2, p.1575-1585, 2012.

PASSARETTI, T.; GUARNIERI, A. P.; FILIPINI, R.; ALVES, B. D. C. A.; FONSECA, F. L. A. Eficácia do uso do Barbatimão (Stryfhnodendron barbatiman) no processo de cicatrização em lesões: uma revisão de literatura. ABCS Health Sciences, v41, n.1, p. 51-54, 2016.

PEIXOTO NETO, PA DE S.; AZEVEDO, J. L.; ARAÚJO, W. L. Microrganismos endofíticos. Biotecnologia Ciência \& Desenvolvimento, v. 29, p. 62-77, 2002. 
PRADA, H.; AVILA, L.; SIERRA, R.; BERNAL, A.; RESTREPO, S. Caracterización morfológica y molecular del antagonismo entre el endofito Diaporthe sp. aislado de frailejón (Espeletia sp.) y el fitopatógeno Phytophthora infestans. Revista Iberoamericana de Micología, v. 26, n. 3, p. 198-201, 2009.

QUIROGA, E. N.; SAMPIETRO, A. R.; VATTUONE, M. Screening antifungal activitis of selected medicinal plants. Journal of Ethnopharmacology, v. 74, p. 89 96, 2001.

RAEDER U, BRODA P (1985) Rapid preparation of DNA from filamentous fungi. Lett Appl Microbiol 1:17-20

RODRIGUEZ, P.; GONZALEZ, D.; GIORDANO, S. R. Endophytic microorganisms: A source of potentially useful biocatalysts. Journal of Molecular Catalysis B: Enzymatic, 2017.

SHETTY, K. G.; RIVADENEIRA, D. V.; JAYACHANDRAN, K.; WALKER, D. M. Isolation and molecular characterization of the fungal endophytic microbiome from conventionally and organically grown avocado trees in South Florida. Mycological progress, v. 15, n. 9, p. 977-986, 2016.

SIA, E. F.; MARCON, J.; LUVIZOTTO, D. M.; QUECINE, M. C.; TSUI, S., PEREIRA; J. O.; PIZZIRANI-KLEINER, A. A.; AZEVEDO, J. L. Endophytic fungi from the Amazonian plant Paullinia cupana and from Olea europaea isolated using cassava as an alternative starch media source. SpringerPlus, v. 2, n. 1, p. 579, 2013.

SILVA, M. C. S. Bioprospecção e caracterização de microrganismos endofíticos de isolados de sementes de guaranazeiro e o controle da antracnose (Colletotrichum spp.). Tese de Doutorado. Universidade de São Paulo, 2015.

SILVA FILHO, G. N.; VIDOR, C. Atividade de micro-organismos solubilizadores de fosfatos na presença de nitrogênio, ferro, cálcio e potássio. Pesquisa Agropecuária Brasileira, Brasília, v.36, p.1495-1508, 2001.

SOUSA, C. P.; SERRANO, N. F. G.; LACAVA, P. T. Endophytic Microorganisms of the Tropical Savannah: A Promising Source of Bioactive Molecules. Diversity and Benefits of Microorganisms from the Tropics. Springer, Cham, p. 57-70ringer, 2017.

SUN, S.; ZENG, X.; ZHANG, D.; GUO, S. Diverse fungi associated with partial irregular heartwood of Dalbergia odorifera. Scientific reports, v. 5, p. 8464, 2015.

SUNITHA, V. H.; DEVI, D. N.; SRINIVAS, C. Extracellular enzymatic activity of endophytic fungal strains isolated from medicinal plants. World Journal of Agricultural Sciences, v. 9, n. 1, p. 01-09, 2013.

SURYANARAYANAN, T. S.; VENKATESAN, G.; MURALI, T. S. Endophytic fungal communities in leaves of tropical forest trees: diversity and distribution patterns. Current Science, p. 489-493, 2003. 
UDAYANGA, D., LIU, X., MCKENZIE, E. H., CHUKEATIROTE, E., BAHKALI, A. H., HYDE, K. D. The genus Phomopsis: biology, applications, species concepts and names of common phytopathogens. Fungal Diversity, v. 50, n. 1, p. 189, 2011.

UZOR, PHILIP F.; OSADEBE, PATIENCE O.; NWODO, NGOZI J. Antidiabetic activity of extract and compounds from an endophytic fungus Nigrospora oryzae. Drug research, v. 67, n. 5, p. 308-311, 2017.

VIEIRA M.L.A. Bioprospecção da atividade antimicrobiana de fungos endofíticos ssociados a Solanum cernuum vell.(Solanaceae). Dissertação de mestrado, UFMG. Universidade Federal de Minas Gerais, 2008.

VIEIRA, M. L.; JOHANN, S.; HUGHES, F. M.; ROSA, C. A.; ROSA, L. H. The diversity and antimicrobial activity of endophytic fungi associated with medicinal plant Baccharis trimera (Asteraceae) from the Brazilian savannah. Canadian journal of microbiology, v. 60, n. 12, p. 847-856, 2014.

TAN, R. X.; ZOU, W. X. Endophytes: a rich source of functional metabolites. Natural product reports, v. 18, n. 4, p. 448-459, 2001.

TAWFIKE, A. F.; ABBOTT, G.; YOUNG, L.; EDRADA-EBEL, R. MetabolomicGuided Isolation of Bioactive Natural Products from Curvularia sp., an Endophytic Fungus of Terminalia laxiflora. Planta medica, v. 84, n. 3, p. 182-190, 2018.

ZHAO, J. H.; ZHANG, Y. L.; WANG, L. W.; WANG, J. Y.; ZHANG, C. L. Bioactive secondary metabolites from Nigrospora sp. LLGLM003, an endophytic fungus of the medicinal plant Moringa oleifera Lam. World Journal of Microbiology and

Biotechnology, v. 28, n. 5, p. 2107-2112, 2012.

WHITE TJ, BRUNS T, LEE S, TAYLOR J. Amplification and direct sequencing of fungal ribosomal RNA genes for phylogenetics. In: Innis MA, Gelfand DH, Sninsky JJ, White TJ, editors. PCR Protocols: A Guide to Methods and Applications. New York: Academic Press; 1990. p. 315-32. 